\title{
Português indígena,
} Hunsrückisch e português quilombola: um retrato dos contatos linguísticos no Brasil

\author{
Giovana Alves de OLIVEIRA ๑ \\ Universidade Federal de Goiás (UFG)
}

○

OPEN ACCESS

EDITADO POR

Raquel Freitag

AVALIADO POR

Monica Savedra

SOBRE OS AUTORES

Giovana Alves de Oliveira Contribuiu com Bárbara

Heliodora Santos. Papéis: escrita - rascunho original.

Bárbara Heliodora Santos Contribuiu com Giovana Alves de Oliveira. Papéis: escrita rascunho original.

DATAS

Recebido: 18/07/2020 Aceito: 01/09/2020 Publicado: 16/09/2020

COMO CITAR

Oliveira, G. A.; Santos, B. H. (2020). Português indígena, Hunsrückisch e português quiIombola: um retrato dos conta-

tos linguísticos no Brasil. Revista da Abralin, v. 19, n. 2 , p. 1-6, 2020.
Bárbara Heliodora SANTOS (D)

Universidade de Brasília (UnB)

\section{RESUMO}

Neste texto, resenhamos a mesa redonda moderada por Mônica Savedra e debatida por Beatriz Protti Christino, Karen Pupp Spinissé e Silvana Silva de Farias Araujo, intitulada Estudos da Sociolinguística de Contato no Brasil, que ocorreu em 11 de julho de 2020, como parte da série de eventos online organizada pela Abralin ao vivo - linguistas online. Na referida mesa, foram apresentadas e discutidas diferentes perspectivas de pesquisas acerca dos estudos sociolinguísticos de contato linguístico do Português Brasileiro (PB), como é o caso do Português Indígena, das Línguas Brasileiras de Imigração e do Português rural falado em comunidades quilombolas. O objetivo, portanto, é apresentar a pluralidade linguística que se criou no Brasil a partir não só do contato entre as línguas que foram trazidas, de diferentes formas, durante a colonização, como também do contato entre as línguas que aqui já existiam, a fim de demonstrar a riqueza e, sobretudo, a importância identitária e educacional que o estudo, a compreensão e a valorização que essas línguas têm.

\section{ABSTRACT}

In this text, we review the roundtable discussion moderated by Mônica Savedra and debated by Beatriz Protti Christino, Karen Pupp Spinissé and 


\section{REVISTA DA ABRALIN}

Silvana Silva de Farias Araujo, entitled Studies of Sociolinguistics of Contact in Brazil, which took place on July $11^{\text {th }}, 2020$, as part of the series of online events organized by Abralin live - online linguists. At this table, different research perspectives were presented and discussed the sociolinguistic contact studies of Brazilian Portuguese, such as Indigenous Portuguese, Brazilian Immigration Languages, and rural Portuguese spoken in quilombola communities. The objective, therefore, is to present the linguistic plurality that has been created in Brazil from not only the contact between the languages that were brought, in different ways, during colonization, but also the contact between the languages that already existed here, in order to demonstrate the richness and, above all, the identity and educational importance that the study, understanding, and appreciation of these languages have.

PALAVRAS-CHAVE

Sociolinguística. Contato Linguístico. Línguas Minorizadas.

\section{KEYWORDS}

Sociolinguistics. Linguistic Contact. Minimized Languages.

Embora a historiografia brasileira e as políticas linguísticas deste país tenham tentado apagar esta informação, sabe-se, atualmente, que o Brasil é um país multicultural e plurilíngue, onde são faladas de 150 a 180 línguas indígenas, de acordo com Rodrigues (2005), 56 línguas de imigração, conforme Altenhofen (2013), a Libras e outras línguas de sinais, línguas de povos ciganos, além do bilinguismo fronteiriço e da entrada recente de línguas faladas por refugiados. Para além dessas situações de bilinguismo sincrônico, as variedades de Português Brasileiro (PB) faladas em comunidades quilombolas apresentam traços gramaticais oriundos das línguas dos ancestrais. A partir dessa constatação sobre a diversidade linguística, Mônica Savedra organiza a mesa redonda intitulada Estudos da Sociolinguística de Contato no Brasil, com o objetivo de apresentar um estado da arte dos estudos acerca do contato linguístico no Brasil, a partir da perspectiva da Sociolinguística.

Para tanto, a organizadora convida três pesquisadoras que representam três campos de atuação da Sociolinguística de contato: Beatriz Protti Christino (UFRJ), que pesquisa sobre as variedades de Português Indígena; Karen Pupp Spinissé (UFRGS), cujo foco são as línguas de imigração, e Silvana Silva de Farias Araújo (UEFS), a qual tem, como objeto de pesquisa, analisar variedades de comunidades quilombolas.

Atenta à situação gravíssima em que se encontram os povos indígenas no contexto da pandemia, Beatriz Protti Christino ressalta a diversidade de situações de multilinguismo que se dão tanto nas 


\section{REVISTA DA ABRALIN}

relações entre línguas indígenas umas com as outras, que em geral são simétricas, quanto nas relações assimétricas entre o PB e as línguas indígenas. Além das relações citadas, devemos citar ainda as relações assimétricas entre línguas indígenas, como as que ocorrem nos processos de expansão de línguas gerais (BESSA FREIRE, 2004; CRUZ, 2015) e de cooficialização de poucas línguas indígenas em regiões de grande multilinguismo (OLIVEIRA, 2015; SHULIST, 2016). Como exemplo do primeiro caso, a pesquisadora destaca exemplos bem conhecidos, como o multilinguismo do Alto Rio Negro (AIKHENVALD, 1999; 2002) e do Xingu (FRANCHETTO, 2011), e situações multilíngues menos conhecidas, como a que se estabelece entre os Tapirapé (autodenominados Apyawã), pertencentes à família Tupi-Guarani, e os Karajá (autodenominados Inỹ), pertencentes à família Macro-jê. Conforme Praça e Ribeiro (2012), essas duas línguas apresentam empréstimos linguísticos adaptados fonologicamente que atestam contato prolongado e bastante antigo, além de terem intensificado as relações de proximidade, a partir da década de 1950, por meio de casamentos interétnicos.

Ao olhar as variedades de Português falado pelos indígenas, nota-se que elas possuem especificidades, como as adaptações fonológicas e morfossintáticas, além de processos discursivos que permitem a alguns povos criarem uma etiqueta interacional própria. No que diz respeito às adaptações fonético-fonológicas e morfossintáticas, são mencionados alguns trabalhos como o de Emmerich (1984), que observou adaptações em relação às concordâncias de $1^{\circ}$ pessoa do singular na variedade do português falada por povos do Alto do Xingu, de Ferreira (2005), cujas observações revelam uma tendência ao ensurdecimento das oclusivas vozeadas no Português Parakatejê; e Rojas-Brescia, Pereira e Menihako Kuikuro (2020), os quais apontam para a ocorrência de um paragoge em palavras terminadas com consoantes. Para exemplificar especificidades pragmáticas, Christino analisa variedade de Português falada pelo povo Kaxinawá (autodenominados Huni Kuin), pertencentes à família Pano, em que ocorrem não somente adaptações em relação à forma, mas também em relação ao discurso.

Nos dados do Português Kaxinawa coletados por meio de entrevistas sociolinguísticas, foram observadas ocorrências de fórmulas de fechamento de fala, as quais são comuns na língua Kaxinawa, como, por exemplo, o uso de "isso que tou pensando" ou "assim nós trabalha" para finalizar um turno de fala, o que ocorreu com uma considerável frequência na fala dos participantes da pesquisa. Desse modo, reconhecer as variedades do Português indígena é, principalmente, reconhecer os aspectos de identidade e os aspectos culturais trazidos por esses povos em suas variedades linguísticas.

Na sequência, Karen Pupp Spinissé, discute, a partir da perspectiva da Linguística Aplicada (LA), o caso da língua Hunsrückisch, que, como a autora faz questão de destacar, é uma língua brasileira fruto do contato entre o Alemão e o PB.

O Hunsrückisch, assim como as línguas indígenas brasileiras, adquiriu, ao longo dos anos, o status de língua minorizada, tendo em vista que, em razão de visões segregacionistas, essa língua foi taxada como não sendo nem Alemão nem PB. Nesse sentido, a pesquisa desenvolvida pela pesquisadora Spinissé, nas escolas do Rio Grande do Sul, tem como objetivo avaliar, principalmente, o grau de inteligibilidade dos falantes de Hunsrückisch em relação ao Alemão, a fim de demonstrar as inúmeras semelhanças entre ambas as línguas e utilizar o Hunsrückisch como "língua-ponte" para o aprendizado de Alemão dentro das escolas. A partir disso, a pesquisadora defende que usar a língua 


\section{REVISTA DA ABRALIN}

minorizada em sala de aula ajuda a legitimá-la como uma língua que possui valor e torna o aprendizado dos alunos menos traumático. Spinissé ratifica que levar o Hunsrückisch para as salas de aula gera atitudes linguísticas positivas por partes dos falantes em relação à língua que falam.

Embora possa parecer evidente a importância da valorização de línguas como o Hunsrückisch, Spinissé também destaca que a proposta de sua pesquisa, quando apresentada em contexto escolar, não é acolhida por todos, tendo em vista que ainda há, por parte, inclusive, de professores de Língua Portuguesa, a presença de das visões segregacionistas mencionadas, as quais consideram o Hunsrückisch como uma variedade inferior ao PB e ao Alemão.

Por fim, a discussão se volta para as especificidades das variedades de PB quilombola. Para a pesquisadora Silvana Silva de Farias Araújo, as variedades do Português faladas por comunidades quilombolas - particularmente as variedades faladas nas comunidades de Mussuca, em Sergipe; e em Barra e Bananal, na Bahia - apresentam traços da aquisição do Português em situações de intensos contatos linguísticos. Esse intenso contato explicaria diferenças em relação a outras variedades de PB rural, não marcadas etnicamente, com as de Açuzinho, em Sergipe, e a de Lagoa Inácio, na Bahia. Para a pesquisadora, é necessário, sobretudo, compreender quais os tipos de contato que os quilombolas tiveram com outros povos, uma vez que esse foi um contato marcado por uma disparidade racial, socioeconômica e linguística.

Em termos linguísticos, a professora apresenta rapidamente alguns dados de objeto duplo, como "ele deu cachorro menino", em vez de "ele deu o cachorro ao menino" e de perda de flexão de caso, como "a menina que mora mais eu", "quer ir mais eu?"; "bora mais eu?" e construções, como "a casa de eu". Embora os dados apresentados representem as especificidades das variedades de PB quilombola, seria interessante avaliar a estatística de frequência com que esses dados ocorrem para mais bem caracterizar o contraste em relação a variedades de PB rural, não marcadas etnicamente.

A partir das discussões apresentadas na mesa redonda em questão e tendo em vista a existência de um grande número de línguas de contato no Brasil e as suas invisibilidades no meio escolar e no meio social, é preciso fazer o seguinte questionamento: como a linguística tem trabalhado com as línguas de contato?

Sabe-se que a pesquisa sobre línguas de contato começou a crescer no Brasil a partir dos estudos de Dante Lucchesi e Alan Baxter, que estudaram o Português falado pela comunidade Helvécia, localizada na Bahia (LUCCHESI; BAXTER, 1999; 2009) (LUCCHESI, 2001). O avanço dos estudos a respeito das variedades de Português das comunidades quilombolas estão permitindo mais bem compreender a própria formação do PB, a partir do contato com línguas africanas. No entanto, os estudos em Linguística de Contato no Brasil ainda têm muito a crescer, seja a partir da demonstração de processos de mudanças induzidas por contato das variedades do PB quilombola e indígena, das variedades brasileiras das línguas de imigração e das próprias línguas indígenas em contato com o PB; seja a partir dos estudos de interação multilíngue, como os que levam a fenômenos como o codeswitching, ainda pouco estudados no Brasil. Como pôde ser visto na apresentação da mesa feita por Mônica Savedro, se levarmos em conta a diversidade de línguas em contato no Brasil, temos um vasto campo de estudos a explorar. 


\section{REVISTA DA ABRALIN}

Para finalizar, é preciso trazer à memória o Decreto $\mathrm{n}^{\circ} 7.387$, de 2010, mencionado pela professora Mônica Savedra, o qual institui o Inventário Nacional da Diversidade Linguística "como instrumento de identificação, documentação, reconhecimento e valorização das línguas portadoras de referência à identidade, à ação e à memória dos diferentes grupos formadores da sociedade brasileira". Ainda, é importante ratificar a fala da professora Karen Pupp Spinissé, que afirma que existem várias línguas de contato no mundo e que todas têm o mesmo valor.

\section{REFERÊNCIAS}

AIKHENVALD, Alexandra Y. Areal diffusion and language contact in the Içana-Vaupés basin, North West Amazonia. In: DIXON, R. M. W.; AIKHENVALD, Alexandra Y. (org.). The Amazonian Languages. Cambridge: Cambridge University Press, 1999. p. 385-416.

AIKHENVALD, Alexandra Y. Language contact in Amazonia. New York: Oxford University Press on Demand, 2002.

ALTENHOFEN, Cléo Vilson. Migrações e contatos linguísticos na perspectiva da geolinguística pluridimensional e contatual. Revista de Letras Norte@ mentos, Sinop, v. 6, n. 12, p. 19-43, 2013.

BAXTER, Alan; LUCCHESI, Dante. (1999) Un paso más hacia la definición del pasado criollo del dialecto afro-brasileño de Helvécia (Bahia). In: ZIMMERMANN, K. (org.) Lenguas Criollas de Base Lexical Española y Portuguesa. Frankfurt am Main: Vervuert: 119-141.

BRASIL. Decreto ${ }^{\circ}$ 7.387, de 9 de dezembro de 2010. Institui o Inventário Nacional da Diversidade Linguística e dá outras providências. Constituição: art. 84, inciso VI, Brasília, DF, ano 189, 9 dez. 2010.

CRUZ, Aline da. The rise of number agreement in Nheengatu. Boletim do Museu Paraense Emílio Goeldi. Série Ciências Humanas, Belém, v. 10, n. 2, p. 419-439, 2015.

EMMERICH, Charlotte. A língua de contato no Alto Xingu: forma, origem e função. 1984. Tese (Doutorado em Linguística) - Faculdade de Letras, Universidade Federal do Rio de Janeiro, Rio de Janeiro, 1984.

ESTUDOS da Sociolinguística de Contato no Brasil. Conferência apresentada por Mônica Maria Guimarães Savedra e debatida por Beatriz Protti Christino, Karen Pupp Spinissé e Silvana Silva de Farias Araújo. [s.l., s.n], 2020. 1 vídeo. (1h 49min 30s). Publicado pelo canal da Associação Brasileira de Linguística. Disponível em: https://www.youtube.com/watch?v=4s3NT5lh3eA\&t=1191s. Acesso em: 15 jul 2020.

FERREIRA, Marília. Descrição de aspectos da variante étnica usada pelos Parkatêjê. D.E.L.T.A: Documentação de Estudos em Linguística Teórica e Aplicada, São Paulo, v. 21, n. 1, p. 1-21, 2005.

FRANCHETTO, Bruna. Evidências linguísticas para o entendimento de uma sociedade multilíngue: o Alto do Xingu. In: FRANCHETTO, Bruna. (org.). Alto Xingu: uma sociedade multilíngue. Rio de Janeiro: Museu do Índio/Fundação Nacional do Índio, 2011. p. 3-38.

FREIRE, José Ribamar Bessa. Rio Babel: a história das línguas na Amazônia. Rio de Janeiro: Eduerj, 2004.

LUCCHESI, Dante. As duas grandes vertentes da história sociolingüística do Brasil (1500-2000). D.E.L.T.A: Documentação de Estudos em Linguística Teórica e Aplicada, São Paulo, v. 17, n. 1, p. 97-130, 2001. 


\section{REVISTA DA ABRALIN}

OLIVEIRA, Gilvan Müller de. A cooficialização de línguas em nível municipal no Brasil: direitos linguísticos, inclusão e cidadania. In: MORELLO, Rosângela (ed.). Leis e Línguas no Brasil: o processo de cooficialização e suas potencialidades. Florianópolis: IPOL, 2015, p. 23-30.

PRAÇA, W. N.; RIBEIRO, E. R. Language contact between karajá (Macro-Jê) and tapirapé: past and present. In: INTERNATIONAL CONGRESS OF AMERICANISTS: BUILDING DIALOGUES IN THE AMERICAS, 54., 2012, Viena, Austria. Resúmenes Abstracts. Anais [...]. Viena: ICA, 2012. p. 1704.

RODRIGUES, Aryon Dall'Igna. Sobre as línguas indígenas e sua pesquisa no Brasil. Ciência e Cultura, São Paulo, v. 57, n. 2, p. 3538,2005 .

ROJAS-BERSCIA, Luis Miguel; PEREIRA, Douglas William; MEHINAKU KUIKURO, Makulan. O português dos jovens da aldeia Afukuri: notas sobre o contato linguístico no Alto Xingu. Revista Brasileira de Linguística Antropológica, Brasília, v. 12, n.s/n, p. 21-39, 2020.

SHULIST, Sarah. In the House of Transformation: Language revitalization, state regulation, and indigenous identity in urban Amazonia. PhD Dissertation. London, Ontario: University of Western Ontario, 2013. 